\title{
The Effects of Progesterone Therapy on the Gestation Length and Reduction of Neonatal Complications in Patients who had Received Tocolytic Therapy for Acute Phase of Preterm Labor
}

\author{
Marzie Lotfalizadeh ${ }^{1, *}$, Nayereh Ghomian ${ }^{1}$, Amirreza Reyhani ${ }^{1}$ \\ ${ }^{1}$ Women Health Research Center, Department of Gynecology and Obstetrics, Faculty of Medicine, Mashhad University of Medical Sciences, Mashhad, IR Iran \\ ${ }^{*}$ Corresponding author: Marzie Lotfalizadeh, Women Health Research Center, Department of Gynecology and Obstetrics, Faculty of Medicine, Mashhad University of Medical Sci- \\ ences, Mashhad, IR Iran. Tel: +98-511-8022608, Fax: +98-511-8525305, E-mail: lotfalizadehm@mums.ac.ir
}

Received: August 29, 2012; Revised: October 13, 2012; Accepted: January 08, 2013

\begin{abstract}
Background: While tocolytic therapy can halt the process of delivery, some patients return before the 37th week of pregnancy with recurrence of preterm labor signs.

Objectives: This study was designed to evaluate the efficacy of progesterone in the prolonging of gestation and reduction of neonatal complications.

Material and Methods: In a clinical trial in 2010,110 singleton pregnant women admitted at Imam Reza Hospital, Mashhad, Iran, with the diagnosis of preterm labor were divided into three groups: $400 \mathrm{mg} / \mathrm{d}$ vaginal progesterone suppositories; $250 \mathrm{mg} / \mathrm{w}$ 17-alpha-hydroxylprogestrone-caproate; and a control group with no additional treatment. After delivery, we assessed the duration between the first phases of labor to the recurrence of preterm labor. The neonatal complications, apgar score, birth weight, need for admission to NICU, and congenital malformations were compared between groups.

Results: The mean gestational age was $34 \pm 3$ weeks in the first, $33.5 \pm 3$ weeks in the second and $32.5 \pm 2$ weeks in the control group. The duration of first phase of labor was $31 \pm 17$ days in the first, $36 \pm 14$ days in the second and $26 \pm 22$ days in the control group. The difference between study groups and the control group was significant $(\mathrm{P}<0.005)$. The complications were lower in progesterone-receiving group in comparison to the control group.

Discussion: This study reveals that progesterone can significant reduce the rate of recurrent preterm labor and the several possible neonatal complications among women who had treated with tocolytics to suppress the acute phase.
\end{abstract}

Keywords: Premature Birth; Progesterone; Gestational Age; Tocolysis; Hydroxyprogesterones; Apgar Score

\section{Background}

Prematurity is considered as one of the major etiologies of neonatal mortality. $(1,2)$. Currently, tocolytic therapy by beta-adrenergic agonists, calcium-channel-blockers, and oxytocin antagonistsis and progesterone for prevention of preterm labor is considered the main strategy to solve this issue $(3,4)$. These medicines are used to target the responsible stimuli for induction of delivery. While they are not clearly identified, several mechanisms such as change in the amniotic fluid eicosanoid concentrations, (5) amniotic fluid cell death nucleosomes' levels, (6) inflammation and subsequent alteration in the concentration of cytokines, (7) systemic or local alteration in levels of steroidal hormones, $(8,9)$ and cervical length, (10) has been proposed. It is demonstrated that amniotic fluid F2-isoprostane, PGE2, and PGD2 have higher concentrations at term while in preterm births, there is up- per level of PGF2 $\alpha$. (5). Furthermore, Soloff showed that progesterone can reduce uterine excitability by affecting the expression of calcium and voltage-operated $\mathrm{K}(+)$ channels and down-regulation of receptors involved in myometrial contraction and the proteins involved in the cross-linking of actin and myosin filaments to produce uterine contractions (9). In addition to prevention from delivery, pre-labour progesterone has now several other indications such as in threatened abortion, supporting luteal phase in IVF and management of preterm labour. (11-13). Another indication for progesterone in pregnancy is the maintenance therapy in preterm labour (14). While tocolytic therapy can halt the process of delivery, (15-17) some patients return before the 37 th week of pregnancy with recurrence of preterm labour signs. Those above 34 th week do not need tocolytic therapy any more, but as it is still preterm situation, the neonates might need to be admitted at NICU and the risk of complications still per-

Implication for health policy/practice/research/medical education:

Weekly injections of 17-alpha-hydroxyl-progestrone-caproate as well as vaginal progesterone either in injection form or suppository can lead to a significant reduction in the rate of recurrent preterm labor and neonatal complications among women who had treated with tocolytics to suppress the acute phase.

Copyright (C) 2013, Iranian Red Crescent Medical Journal; Licensee Kowsar Corp. This is an Open Access article distributed under the terms of the Creative Commons Attribution License (http://creativecommons.org/licenses/by/3.0), which permits unrestricted use, distribution, and reproduction in any medium, provided the original work is properly cited. 
sists (18). Therefore, to prevent recurrence, increasing the length of pregnancy and acquiring better birth weight, some patients are treated with oral tocolytics as a maintenance therapy (19); however, this strategy is controversial and some other medications such as Atosiban and progesterone have been suggested for the maintenance therapy $(14,20)$. There are some evidences that progesterone can be used in this phase. Intra-muscular (IM) weekly injection of 17-alpha-hydroxyl-progestrone-caproate is an appropriate medication for those at risk of preterm labour. (21). This important clinical trial shows that in comparison to women receiving placebo, they had lower risk of preterm labour and perinatal mortality. The efficacy of vaginal progesterone suppositories in lowering the rate of preterm labour has also been reported. (22). However, there are studies that explain the lack of effectiveness of progesterone in prolonging pregnancy $(23,24)$.

\section{Objectives}

Our study was designed to evaluate the efficacy of progesterone maintenance therapy in the patients who had received tocolytic therapy for preterm labour.

\section{Patients and Methods}

In a clinical trial in 2010, singleton pregnant women admitted at Imam Reza Hospital, Mashhad, Iran, with the diagnosis of preterm labour were assessed regarding length of gestation and neonatal complications following progesterone maintenance therapy. The diagnosis was based on the presence of at least four contractions per minute, accompany to $2 \mathrm{~cm}$ dilatation, or $80 \%$ effacement, or progressive cervical changes (dilatation of $1 \mathrm{~cm}$ per hour). Inclusion criteria were gestational age of 26 to 36 weeks (according to an accurate LMP or first-trimester ultrasound), singleton pregnancy, premature contraction and cervical changes with intact amniotic membrane. Exclusion criteria were chorioamnionitis, fever, evidence of IUGR, oligohydroaminos, fetal abnormalities, gestational diabetes and hypertension or any other maternal or fetal medical complications, any contraindication for tocolytic therapy, dilatation $4 \mathrm{~cm}$ or more, progression towards delivery despite of treatment with tocolytic and any indication for urgent termination of pregnancy by cesarean section. All the patients referring to the hospital with initial diagnosis of preterm labour were first rehydrated by Ringer Lactate $1000 \mathrm{cc}$ in an hour and received analgesic (50 $\mathrm{mg}$ pethidine IV). If the contractions were not true and became suppressed, there was no need for additional treatments and patients were excluded from the study. Otherwise, magnesium sulfate with a loading dose of $4 \mathrm{~g}$ IV and maintenance dose of 1 $2 \mathrm{~g}$ per hour or nifedipine one tablet each 20 minutes up to three doses as a loading dose and one tablet each six hours up to 24 hours as a maintenance dose was started. Twelve hours after cessation of contractions, we stopped tocolytic therapy. In addition, all patients received be- tametasone $12 \mathrm{mg} /$ day IM up to two doses and ampicillin 1 $\mathrm{g} / 6 \mathrm{~h}$ up to 48 hours and then oral amoxicillin $500 \mathrm{mg} / 6 \mathrm{~h}$ and erythromycin $400 \mathrm{mg} / 6 \mathrm{~h}$ for 5 days. After the control of premature contractions and 24 hours follow-up, information about the maintenance therapy and the aims and process of the research was given to the patients. Signing a written consent according to the guidelines of the ethics committee of Mashhad University of Medical Sciences, volunteers were divided into three groups: The first received $400 \mathrm{mg} / \mathrm{d}$ vaginal progesterone suppositories until the 37th gestational week; in the second group, 250mg/w 17-alpha-hydroxyl-progestrone-caproate was given until the 37 th gestational week; the third as a control group received no additional treatment. All the patients were controlled weekly in the high-risk obstetrics clinic of Imam Reza, Mashhad University of Medical Sciences. If any sign of preterm labour was observed, a vaginal examination was performed by the obstetrics and if the initiation of labour was approved, we admitted the patient for possible evaluation of any indication for termination. After delivery, we assessed neonatal complications, apgar score, birth weight, need for admission to NICU, and congenital genitourinary and musculoskeletal malformations and compared them between the study groups. In addition, the duration between the first phases of labor to the recurrence of preterm labor was considered as the prognosis of each treatment modality for prevention of preterm labor.

\section{Results}

From 233 pregnant women admitting to the hospital for preterm labor, only 110 agreed and fulfilled the criteria to continue our study. From these cases, 37 accepted the treatment with $400 \mathrm{mg} / \mathrm{d}$ vaginal progesterone suppositories, 37 received $250 \mathrm{mg} / \mathrm{w}$ 17-alpha-hydroxylprogestrone-caproate and 36 were arrived in the control group. There was no significant difference between these groups regarding the mean age of mothers. The mean gestational age at the time of labor was $34 \pm 3$ weeks in the first, $33.5 \pm 3$ weeks in the second and $32.5 \pm 2$ weeks in the control group. This difference was not significant among the groups $(\mathrm{P}>0.05)$. The duration of first phase of labour was $31 \pm 17$ days in the first, $36 \pm 14$ days in the second and $26 \pm 22$ days in the control group. There was no difference between the first and second groups; however, the difference between study groups and the control group was significant $(\mathrm{P}<0.005)$. The percentages of perinatal complications including low birth weight (<2500 g), NICU admissions and neonatal infections were lower in progesterone-receiving groups in comparison to the control group (27\% vs. $50 \%, 24.5 \%$ vs. $38.5 \%$ and $3 \%$ vs. $8.5 \%$, respectively) (Table 1 ). There was no case of congenital genitourinary and musculoskeletal malformations in the neonates of each group and none of the mothers receiving progesterone complained from common hormonal complications such as headache, fluid congestion or mood change. 
Lotfalizadeh Met al.

\begin{tabular}{|c|c|c|c|c|c|}
\hline \multirow[t]{2}{*}{ Perinatal Complications } & \multicolumn{2}{|c|}{ Case Groups } & \multirow{2}{*}{$\begin{array}{l}\text { The mean between } \\
\text { Two Case Groups }\end{array}$} & \multirow[t]{2}{*}{ Control group } & \multirow[t]{2}{*}{ Pvalue } \\
\hline & First & Second & & & \\
\hline Low birth weight $(<2500 \mathrm{~g})$, No., (\%) & $10(27)$ & $10(27)$ & $20(27)$ & $18(50)$ & 0.02 \\
\hline NICU admissions, No., (\%) & $10(27)$ & $8(21.5)$ & $18(24.5)$ & $14(38.5)$ & 0.11 \\
\hline Neonatal infections, No., (\%) & $1(3)$ & $1(3)$ & $2(3)$ & $3(8.5)$ & 0.21 \\
\hline Duration of first phase of labor, Mean \pm SD & $31 \pm 17$ & $36 \pm 14$ & $33.5 \pm 15$ & $26 \pm 22$ & $<0.01$ \\
\hline
\end{tabular}

\section{Discussion}

The incidence of preterm labor has increased globally and the management of this complication is still challenging $(14,15,23,25-27)$. Even for the treatment of acute phase, some insist that beta-adrenergic agonists, calcium-channel-blockers, and oxytocin antagonists are the first-line medications (25) while others believe that the only effective tocolytic drugs are the prostaglandin inhibitors and magnesium sulfate should not be used to treat premature labor (26). In this clinical trial, efficacy of progesterone maintenance therapy after treatment with tocolytics for preterm labor was assessed and approved. It seems that it can preserve the relaxation made by the initial tocolytic therapy for the acute phase of preterm labor. Thus, a considerable reduction in the complications such as low birth weight, NICU admissions, and neonatal infection is achievable, as it is shown that the length of gestation has a significant impact on the neonatal complications and mortality (28). Some studies support the findings of our study (29-32). For instance, it is shown that 17-alpha-hydroxyl-progestrone-caproate when prescribed as weekly injections for those at risk of preterm labor can prolong pregnancy. So the patients had lower risk of preterm labor and perinatal mortality (21). Facchinetti showed that it can reduce the incidence both in nuli- and pluriparous women with a previous history of preterm labor (29). Data about the efficacy of vaginal progesterone suppositories in lowering the rate of preterm labor has been previously reported. In this study, prophylactic application of vaginal progesterone suppositories in women significantly reduced the risk of preterm labor and perinatal mortality (22). In addition, the risk of neuromuscular, limb, genitourinary and gastrointestinal abnormalities is not higher in those treated with progesterone in the late pregnancy comparing to the control group. However, there are still some controversies regarding the optimal formulation, route of administration, dose, and gestational age at initiation $(24,31)$. It should also be noticed that the effects of progesterone are related to the vehicle used and the route and time of administration (33). As mentioned above, the main routes are intra-muscular and suppository, whilst the oral route seems to be non-beneficial (23). However, an important study has revealed that women receiving 17-alpha-hydroxyl-progestrone-caproate prophylaxis be- fore 27 weeks' gestation might have even an increased risk for preterm labor (34). Furthermore, it should be kept in mind that progesterone has no role in the prevention of preterm labor in twin pregnancy $(35,36)$ weekly injections of 17-alpha-hydroxyl-progestrone-caproate as well as vaginal progesterone suppositories can lead to a significant reduction in the rate of recurrent preterm labor among women who had treated with tocolytics to suppress the acute phase and also there is a considerable reduction in the neonatal complications. However, it seems that further future studies are needed to accurately define the mechanism of action of progesterone drugs in the prevention of preterm labor and to establish the optimal formulation, route of administration, dose, and gestational age at initiation.

\section{Acknowledgements}

The authors are thankful to all co-workers from women health research center, Imam-Reza hospital of Mashhad.

\section{Authors' Contribution}

None declared.

\section{Financial Disclosure}

The authors have nothing to disclose.

\section{Funding Support}

This study has been financially supported by Medical Faculty of Mashhad University of Medical Sciences.

\section{References}

1. Hadavi M, Alidalaki S, Abedininejad M, Akhavan S. Etiologies and contributing factors of perinatal mortality: a report from southeast of Iran. Taiwan J Obstet Gynecol. 2011;50(2):145-8.

2. Simmons LE, Rubens CE, Darmstadt GL, Gravett MG. Preventing preterm birth and neonatal mortality: exploring the epidemiology, causes, and interventions. Semin Perinatol. 2010;34(6):408-15.

3. Haas DM, Imperiale TF, Kirkpatrick PR, Klein RW, Zollinger TW, Golichowski AM. Tocolytic therapy: a meta-analysis and decision analysis. Obstet Gynecol. 2009;113(3):585-94.

4. Miller DD. Tocolytic therapy for the prevention of preterm labor. J Intraven Nurs. 1995;18(5):223-8.

5. Menon R, Fortunato SJ, Milne GL, Brou L, Carnevale C, Sanchez SC, et al. Amniotic fluid eicosanoids in preterm and term births: effects of risk factors for spontaneous preterm labor. Obstet $G y$ necol. 2011;118(1):121-34.

6. Puchner K, Iavazzo C, Gourgiotis D, Boutsikou M, Baka S, Hassia- 
kos D, et al. The implication of second-trimester amniotic fluid TNF-alpha, cytochrome $\mathrm{C}$ and cell death nucleosomes in the prediction of preterm labor and/or premature rupture of membranes. Arch Gynecol Obstet. 2012;285(1):37-43.

7. Kovo M, Schreiber L, Ben-Haroush A, Asalee L, Seadia S, Golan A, et al. The placental factor in spontaneous preterm labor with and without premature rupture of membranes. J Perinat Med. 2011;39(4):423-9.

8. Marconi C, de Andrade Ramos BR, Peracoli JC, Donders GG, da Silva MG. Amniotic fluid interleukin-1 beta and interleukin-6, but not interleukin-8 correlate with microbial invasion of the amniotic cavity in preterm labor. Am J Reprod Immunol. 2011;65(6):54956.

9. Soloff MS, Jeng YJ, Izban MG, Sinha M, Luxon BA, Stamnes SJ, et al. Effects of progesterone treatment on expression of genes involved in uterine quiescence. Reprod Sci. 2011;18(8):781-97.

10. Wulff CB, Ekelund CK, Hedegaard M, Tabor A. Can a 15-mm cervical length cutoff discriminate between low and high risk of preterm delivery in women with threatened preterm labor? Fetal Diagn Ther. 2011;29(3):216-23.

11. Ludwig M, Diedrich K. Evaluation of an optimal luteal phase sup port protocol in IVF. Acta Obstet Gynecol Scand. 2001;80(5):452-66

12. Penzias AS. Luteal phase support. Fertil Steril. 2002;77(2):318-23.

13. Szekeres-Bartho J, Wilczynski JR, Basta P, Kalinka J. Role of progesterone and progestin therapy in threatened abortion and preterm labour. Front Biosci. 2008;13:1981-90.

14. Meis PJ, Connors N. Progesterone treatment to prevent preterm birth. Clin Obstet Gynecol. 2004;47(4):784-95. ; discussion 881-2.

15. Abou-Ghannam G, Usta IM, Nassar AH. Indomethacin in pregnancy: applications and safety. Am J Perinatol. 2012;29(3):175-86.

16. Chalermchockcharoenkit A, Rattanachaiyanont M, Kongjeera A, Pimol K, Sirisomboon R, Yusamran C. Two different treatment regimens in women with preterm contractions who were admitted to a hospital due to a presumptive diagnosis of preterm labor: an observational study.J Obstet Gynaecol Res. 2008;34(3):3439.

17. Kim A, Shim JY. Emerging tocolytics for maintenance therapy of preterm labour: oxytocin antagonists and calcium channel blockers. BJOG. 2006;113 Suppl 3:113-5.

18. Claris O, Gay C, Putet G, Salle BL. [Neonatal mortality and morbidity of low birth weight premature infants (less than or equal to 1500 g)]. Pediatrie.1991;46(11):751-6.

19. Di Renzo GC, Roura LC, Facchinetti F, Antsaklis A, Breborowicz G, Gratacos E, et al. Guidelines for the management of spontaneous preterm labor: identification of spontaneous preterm labor, diagnosis of preterm premature rupture of membranes, and preventive tools for preterm birth. J Matern Fetal Neonatal Med. 2011;24(5):659-67.

20. Valenzuela GJ, Sanchez-Ramos L, Romero R, Silver HM, Koltun WD, Millar L, et al. Maintenance treatment of preterm labor with the oxytocin antagonist atosiban. The Atosiban PTL-098 Study Group. Am J Obstet Gynecol. 2000;182(5):1184-90

21. Meis PJ, Klebanoff M, Thom E, Dombrowski MP, Sibai B, Moawad
$\mathrm{AH}$, et al. Prevention of recurrent preterm delivery by 17 alphahydroxyprogesterone caproate. N Engl J Med. 2003;348(24):237985.

22. da Fonseca EB, Bittar RE, Carvalho MH, Zugaib M. Prophylactic administration of progesterone by vaginal suppository to reduce the incidence of spontaneous preterm birth in women at increased risk: a randomized placebo-controlled double-blind study. Am J Obstet Gynecol. 2003;188(2):419-24.

23. Meis PJ. 17 hydroxyprogesterone for the prevention of preterm delivery. Obstet Gynecol. 2005;105(5 Pt 1):1128-35.

24. Vidaeff AC, Ramin SM. From concept to practice: the recent history of preterm delivery prevention. Part II: Subclinical infection and hormonal effects. Am J Perinatol. 2006;23(2):75-84.

25. Carbonne B, Tsatsaris V. [Which tocolytic drugs in case of preterm labor?]. J Gynecol Obstet Biol Reprod (Paris). 2002;31(7 Suppl):5S96-104.

26. Higby K, Xenakis EM, Pauerstein CJ. Do tocolytic agents stop preterm labor? A critical and comprehensive review of efficacy and safety. Am J Obstet Gynecol. 1993;168(4):1247-56. ; discussion 56-9.

27. Katz VL, Farmer RM. Controversies in tocolytic therapy. Clin $\mathrm{Ob}$ stet Gynecol.1999;42(4):802-19.

28. Schlesinger ER, Allaway NC. The combined effect of birth weight and length of gestation on neonatal mortality among single premature births. Pediatrics. 1955;15(6):698-704.

29. Facchinetti F, Vaccaro V. Pharmacological use of progesterone and 17-alpha-hydroxyprogesterone caproate in the prevention of preterm delivery. Minerva Ginecol. 2009;61(5):401-9.

30. How HY, Barton JR, Istwan NB, Rhea DJ, Stanziano GJ. Prophylaxis with 17 alpha-hydroxyprogesterone caproate for prevention of recurrent preterm delivery: does gestational age at initiation of treatment matter? Am J Obstet Gynecol. 2007;197(3):260 e1-4.

31. Khadem N, Mousavifar N, Bonakdar F, Baradaran Rafie N. A com parative study of intramuscular oil progesterone injection and suppository progesterone for luteal phase support in patients undergoing IUI csycles. Iran J Obst Gyn Infertil. February-March 2011;13(6):1-5.

32. Saghafi N, Khadem N, Mohajeri T, Shakeri MT. Efficacy of 17alphahydroxyprogesterone caproate in prevention of preterm delivery. J Obstet Gynaecol Res. 2011;37(10):1342-5.

33. Lucovnik M, Kuon RJ, Chambliss LR, Maner WL, Shi SQ, Shi L, et al. Progestin treatment for the prevention of preterm birth. Acta Obstet Gynecol Scand. 2011;90(10):1057-69.

34. Joy S, Rhea DJ, Istwan NB, Desch CN, Stanziano G. The risk for preterm labor in women receiving 17 alpha-hydroxyprogesterone caproate prophylaxis for preterm birth prevention. Am J Perinatol. 2010;27(4):343-8.

35. Combs CA, Garite T, Maurel K, Das A, Porto M. 17-hydroxyprogesterone caproate for twin pregnancy: a double-blind, randomized clinical trial. Am J Obstet Gynecol. 2011;204(3):221 e1-8.

36. Lei K, Chen L, Cryar BJ, Hua R, Sooranna SR, Brosens JJ, et al. Uterine stretch and progesterone action. J Clin Endocrinol Metab. 2011;96(6):E1013-24. 